\title{
Optimisation of Permanent magnet machine topologies suitable for solar powered aircraft
}

\author{
S.Ullah, M.Kimiabeigi, B.Scholes, A.Steven, W.Davis, , R.Wrobel, J. Widmer
}

\begin{abstract}
Electrification of aircraft has become a hot topic in recent years both in civil aviation and unmanned aerial vehicles. The latter domain is gaining in popularity for its high altitude applications, particularly for bringing widespread internet coverage.

This paper presents the work done on the optimisation of different types and topologies of permanent magnet electrical machines that can be considered as the main contenders for such application. These topologies consist of both laminated steel core and airgap winding machines. Instead of copper, compressed aluminium windings were considered which will help in reducing the overall mass of the stator. All the topologies were simulated both under take-off and cruise condition. Each machine had to fulfil a certain thermal constraint (current density) before being simulated at cruise condition in order to find the objective function of the final design. The best topology was chosen based on high efficiency in cruise condition with reduced mass.
\end{abstract}

Index Terms-Unmanned air vehicles, Electrical machines, Airgap winding machines, laminated steel machines, Halbach Array, optimisation, Compressed Aluminium windings

\section{NOMENCLATURE}

PM- Permanent magnet

DRHB-Double rotor Halbach array

SRAW-Single rotor airgap windings

FEA-Finite element analysis

2DFE- Two dimensional finite element

3DFE-Three dimensional finite element

q- slots/pole/phase

J-current density

$J_{\text {critioal-critical current density }}$

\section{INTRODUCTION}

$\mathrm{S}$ olar powered aeroplanes can be a good option to replace satellites which can cost millions between launch, development, cost and maintenance. These "high altitude pseudo satellites" can execute all the functions of current satellites, with lower cost; and the advantage of returning back for power and tech upgrades. They can be used for the weather forecast and environmental monitoring. Together it will be enable real-time mapping, internet and number of surveillance opportunities to meet a broad range of requirements. This will also help in eliminating space junk and declutter low earth orbit. The large solar panels on the aircraft charges the batteries, which in turn drives the electrical machine and hence the propeller. In order to make effective use of this battery power, the electrical machine should be very efficient with a very light weight.

The first flight of a solar powered aircraft took place in 1974 in California (ARPA) and lasted for 20 minutes[1]. In 1994,

This paper is an outcome of the work undertaken as part of the Airbus UK solar powered aircraft project. The authors are with the School of Engineering, Newcastle university, sana.ullah@ncl.ac.uk ben.scholes@newcastle.ac.uk; mohammad.kimiabeigi@newcastle.ac.uk; andy.steven@newcastle.ac.uk; rafal.wrobel@newcastle.ac.uk james.widmer@newcastle.ac.uk
NASA started a programme by the name of "Environmental Research Aircraft Sensor Technology" (ERAST) to build a solar powered aircraft that could reach up to $50,000 \mathrm{ft}$. The Helios prototype based on this programme was able to reach a record $96,000 \mathrm{ft}$. The flight time recorded for this aircraft was 40 minutes [2]. In 2010 the QinetiQ Zephyr aircraft made a world record of continuous unsupported flight duration of more than 14 days with an altitude of over $60,000 \mathrm{ft}$. [3]. In this case, an outer rotor 34 poles 27 slots permanent magnet (PM) electrical machine was used. In 2016, Solar Impulse made a record of flying 40,000 km with two pilots on board in a solar powered aeroplane [4]. The maximum flight time without landing recorded for this aeroplane was 117 hours and 52 minutes. Another recent development in Unmanned Air Vehicle (UAV) is Facebook's Aquila which was tested in 2016 [5]. The maximum flight time recorded in this case was 96 minutes.

This paper presents the work done on the optimisation of different types of permanent magnet machines to achieve the highest efficiency while reducing the overall mass of the machine and its support structure. One of the main challenge in designing the machine is to avoid overheating at take-off condition while still achieving high efficiency in cruise condition. There will be no cooling system surrounding the machine which adds to the challenge. For a thermal constraint, current density is limited to a certain value (J $\left.J_{\text {critical }}\right)$ at take-off condition before the final efficiency of the machine at cruise condition is found.

The three PM types investigated are a fractional slot laminated steel PM machine, a double rotor Halbach array (DRHB) air gap winding machine and a single rotor air gap winding machine with rotating stator coreback (SRAW). Each machine type was optimised with at least 10 iterative cycles to find the global maxima in the objective function. 10JNFE900 steel with a lamination thickness of $0.1 \mathrm{~mm}$ was used within the core to reduce the iron losses [6]. NdFeB magnets with remanence of $1 \mathrm{~T}$ at $100^{\circ} \mathrm{C}$ were used within each machine.

In order to improve the objective function, the best optimised design should have higher efficiency, lower mass and reduced diameter. Based on the optimisation results, the best topology obtained was further simulated for magnet and $\mathrm{AC}$ losses. Due to the compressed windings, AC loss per slot was found by calculating the time variation of flux densities at different slot positions. A Matlab script was used to find the net variations of flux densities per electrical cycle and losses per slot. Magnet losses were reduced by the axial segmentation of the magnets.

\section{OPTIMISATION AND CONSTRAINTS}

\section{A. Optimisation}

All the PM motors were optimised using the Infolytica Optinet software. The optimisation was based on the process flow shown in Fig 1. A 2D (2 dimensional) finite element model of the motor is established, where the optimiser 
stochastically varies the model geometry. A dependency script is then run (more detail to follow) to check that the motor meets key operating requirements and to set optimiser starting conditions. The optimiser itself is run (assessing efficiency in the first cruise condition) and then the penalty function calculated. The optimiser then iterates the process, using its inbuilt evolutionary algorithm (synthetic annealing) to identify optimal solutions until a stable solution is achieved. Previous work has shown that there are often a number of different motor geometries which can achieve similar penalty functions and as a result optimisation is repeated several times to avoid the risk of outlier solutions.

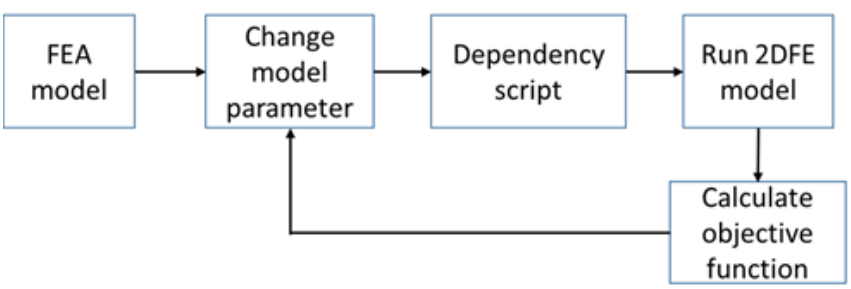

Fig 1: Optinet optimisation model

The dependency script in Fig 2 was used to predict the current density of the machine during the take-off condition, thus eliminating all the solutions with current density (J) above the critical current density (J $J_{\text {critical }}$ ). This script also set-up the model for the optimisation run, confirming the current needed to achieve the cruise condition torque and setting this in the finite element analysis (FEA) model. It also finds the overall mass of the machine (rotor, stator, windings, magnets and support mass).

During the cruise condition, the torque requirement is almost $1 / 3^{\text {rd }}$ to that at the take-off condition. The expected temperature of both magnets and windings is around $-40^{\circ} \mathrm{C}$ in such condition. This significantly reduces the electric loading of the machine. However, at such low temperatures, the high magnet remanence and high electrical conductivity of the windings can result in high magnet and AC losses.

Within the optimisation models, only the DC copper loss and iron losses were calculated. AC and magnet losses were found later for the best model by assuming the use of high strand wires (Litz wire) and segmented magnets which can significantly decrease these losses.

The aerodynamic drag increases as the motor outside diameter increases. Therefore, it was converted into loss to be include within the objective function. Thus, the final objective function is based on the output power, losses (including aerodynamic drag), efficiency and mass of the machine. The slot/pole combinations of the different machines were chosen in such a way to minimise the machine diameter to reduce the aerodynamic drag. To achieve this, a good option can be high slot/pole combinations which will reduce the stator and rotor yoke size. However, a very high pole numbers will result in high leakage flux while high slot numbers will make the process of compressed coils complicated.

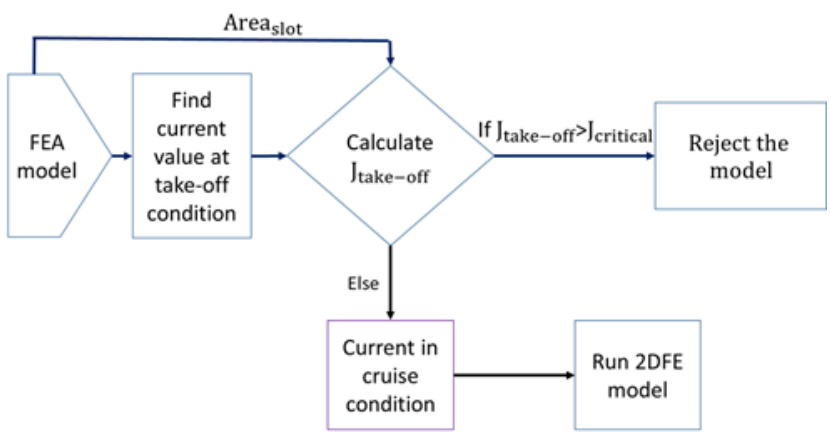

Fig 2: Optinet dependency script model

\section{B. Aluminium windings}

Instead of using copper, aluminium windings were used. The mass density of aluminium is only $30 \%$ that of copper which is significant consideration when considering the motor mass. The aluminium has almost double the thermal conductivity compared to copper windings for the same mass which is important under load condition. Additionally copper wire is significantly more expensive than aluminium wire. In order to achieve the same resistance per winding length, compressed aluminium windings were used to increase the fill factor to $75 \%$. Compressed aluminium windings have already been successfully used in various machines within Newcastle University [7, 8].

\section{Open slot structure}

An open slot stator structure was used in the laminated steel machines. Fig 3 shows the open and closed slot stator structures. The main advantage of the open slot structure is that coil can be wound outside on an aluminium frame, compressed and then inserted in the slots. Coils were compressed to increase the fill factor per slot. The increased fill factor per slot of compressed coils will help the aluminium windings overcome the low electrical conductivity property compared to copper.

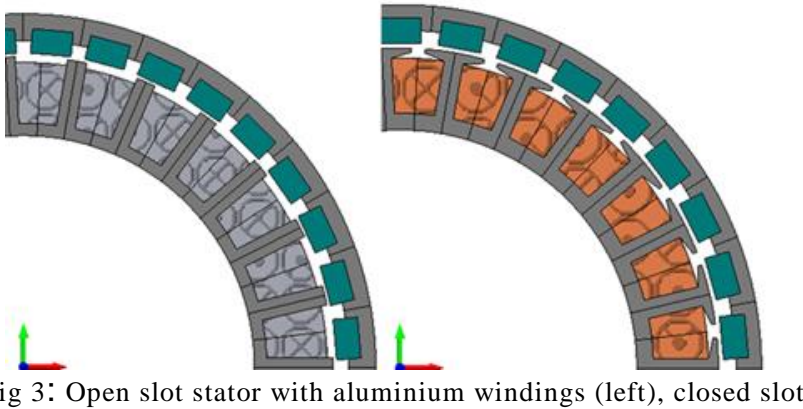
stator with copper windings (right)

\section{MACHINE TOPOLOGIES AND OPTIMISATION RESULTS}

\section{A. Laminated fractional slots machine topologies}

Fractional slot winding machines are gaining popularity for its reduced end winding losses and mass and can be used in fault tolerant applications [9-12].Different slot pole combinations of fractional slot windings were investigated to find the best one with the highest efficiency and lower mass. The chosen topologies are the following with their slots per pole per phase $(\mathrm{q})$ values and winding factors

1. 27 slots 36 poles $(\mathrm{q}=0.25$, winding factor $=0.866$ )

2. 36 slots 32 poles $(\mathrm{q}=0.375$, winding factor $=0.945$ ) 
3. $\mathrm{q}=0.5$ (Optimiser chooses the best combination based on $\mathrm{q}=0.5$, winding factor $=0.866$ )

4. 36 slots 30 poles $(q=0.4$,winding factor $=0.933$ )

The first 3 topologies are double layer winding machines while the $4^{\text {th }}$ one is a single layer winding structure. In case of $q=0.5$, the optimiser was allowed to choose the slot/pole combination to find the best one with the lowest mass and highest efficiency. Table 1 shows the efficiency of each topology at take-off and cruise conditions respectively. Fig 4 shows the comparison of masses (machine mass and support structure mass) of the best machines based on their efficiencies. Individual mass per component of the best topology of 27/36 machine was taken as reference to normalize the masses of other machines.

Table 1: Efficiencies of laminated PM machines at take-off and cruise condition

\begin{tabular}{|l|c|c|}
\hline & Take-off condition (\%) & Cruise condition (\%) \\
\hline $27 / 36$ & 78.14 & 96.24 \\
\hline $36 / 32$ & 78.05 & 96.68 \\
\hline $36 / 30$ & 74.16 & 95.69 \\
\hline $\mathrm{q}=0.5$ & 75.30 & 95.92 \\
\hline
\end{tabular}

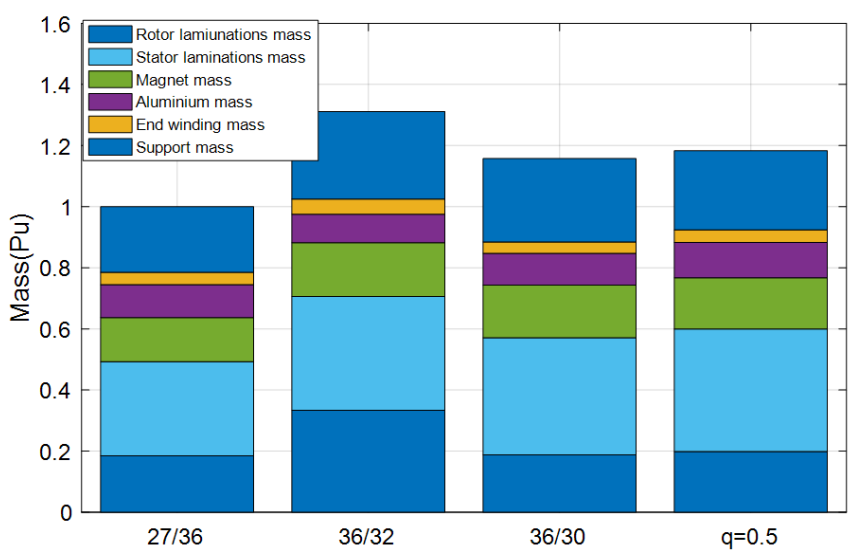

Fig 4: Masses of different parts of machine

Based on the results, it is clear that a $36 / 32$ slot pole combination gives the highest efficiency, however, a 27/36 machine has $22 \%$ less mass and is only $0.4 \%$ lower in efficiency. Based on this, 27/36 machine was chosen as the best topology. Fig 5 shows the design of the 27/36 laminated PM machine design.

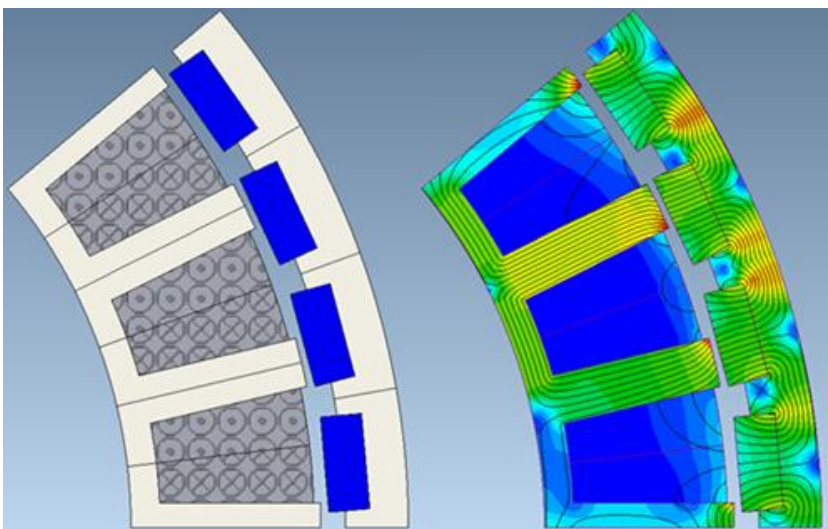

Fig 5: 27/36 laminated PM machine

B. Double rotor Halbach array airgap winding machine (DRHB)

The torque of the PM machine is directly proportional to the field flux, thus to get the maximum air-gap flux density, "Halbach Array" assembly can be a good option. The Halbach arrangement cancels the flux on one side while strengthening it on the other side, meaning no back iron for the rotor is required [13, 14]. Additionally, airgap windings were used within the stator to reduce the overall mass of the stator [15].

For the optimisation, a double rotor 78 slot 26 pole (78/26) distributed air-gap winding machine was chosen. For the

Halbach array design rotor, each pole consists of 4 magnets. The field direction within the magnets was allowed to vary. Based on the simulation results, the best angle found was 30 and 60 degrees with respect to the axial direction. Fig 6 shows the two-dimensional finite element (2DFE) Halbach Array arrangement along with the magnetic field produced.

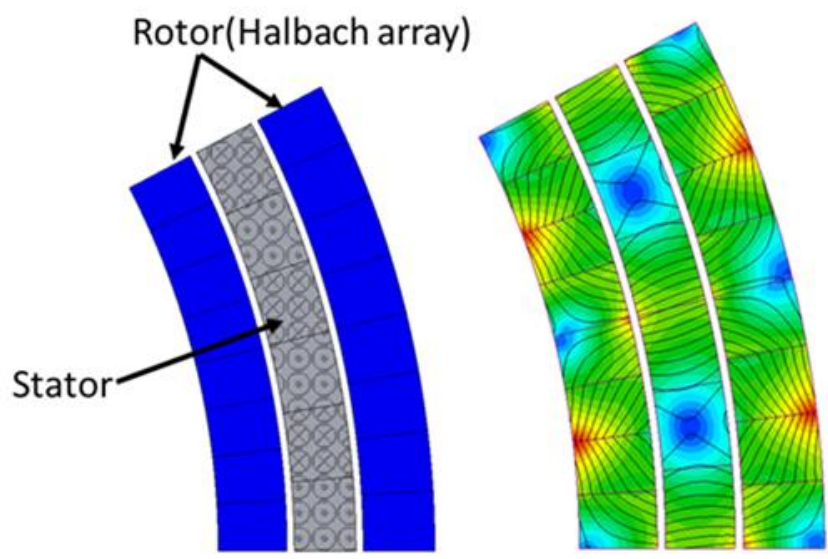

Fig 6: Halbach array with magnetic flux

Table 2 shows the efficiencies of the best DRHB design at take-off and cruise conditions respectively. Table 3 shows the efficiency of the final best design. Fig 7 shows the masses of different components of the machine compare to the 27/36 laminated design taken as a reference.

Table 2: Efficiency of DRHB design at take-off and cruise condition

\begin{tabular}{|c|c|c|}
\hline & $\begin{array}{c}\text { Take-off } \\
\text { condition }(\%)\end{array}$ & $\begin{array}{c}\text { Cruise condition } \\
(\%)\end{array}$ \\
\hline $78 / 26$ DRHB & 77.30 & 97.01 \\
\hline
\end{tabular}




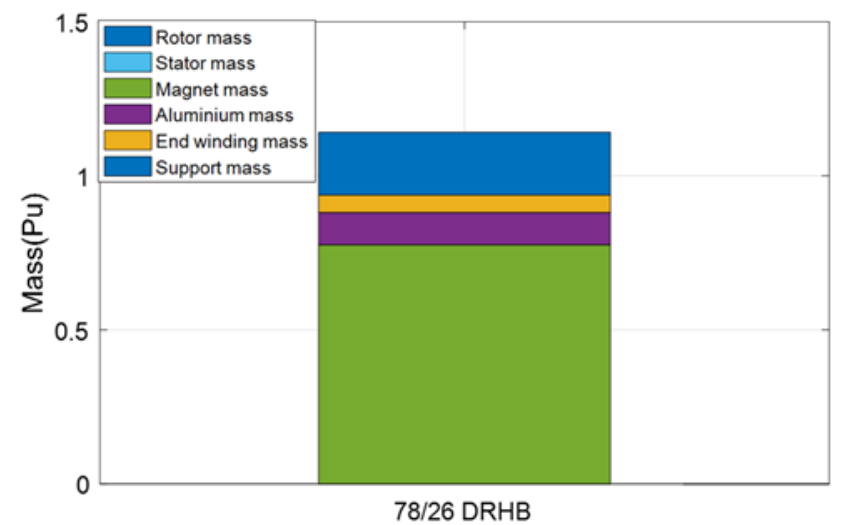

Fig 7: Masses of different parts of DRHB machine

\section{Outer rotor air-gap windings with rotating stator coreback}

The outer rotor airgap winding machine with rotating stator coreback are available commercially and are used within electric model aircraft [16]. The laminated rotor and stator coreback rotate at the same speed as that of the magnets, hence there is almost negligible iron losses within these parts. Within the optimisation model, a 26 pole 78 slot distributed winding machine was optimised with compressed aluminium windings. The simulations were done both at the take-off and cruise conditions. Efficiencies and masses of each model were found. Fig 8 shows the rotor and stator of a tango motor. Fig 9 shows the best optimised model with flux path. Table 3 shows the best optimisation results at take-off and cruise conditions respectively. Fig 10 shows the masses of different parts of the machine compared to the 27/36 laminated design taken as a reference.

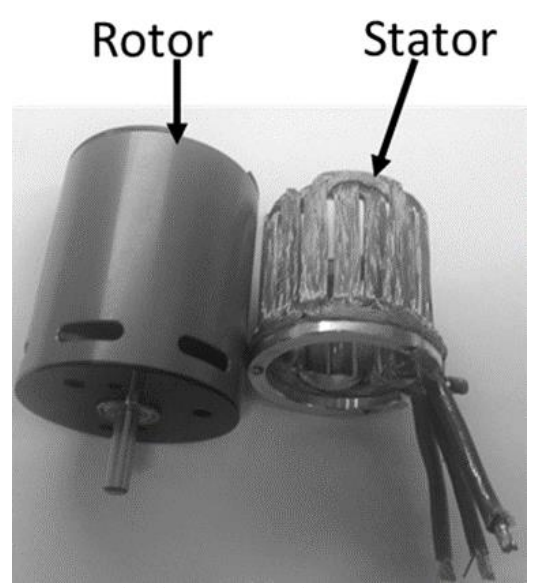

Fig 8: Airgap winding stator(right) and rotor of a tango motor(left)

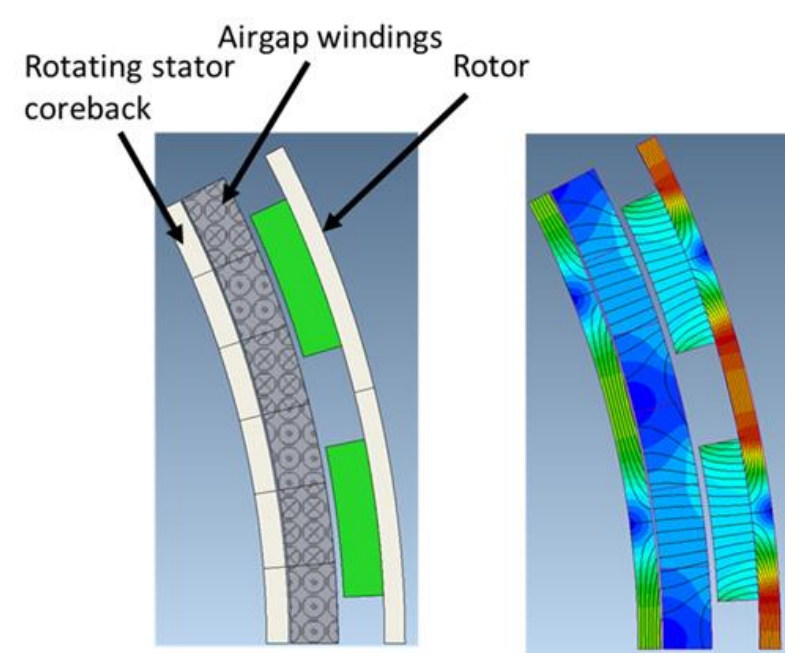

Fig 9: Optimised Airgap winding machine with stator coreback rotating

Table 3: Efficiencies of SRAW design at take-off and cruise condition

\begin{tabular}{|c|c|c|}
\hline & $\begin{array}{c}\text { Take-off } \\
\text { condition }(\%)\end{array}$ & $\begin{array}{c}\text { Cruise condition } \\
(\%)\end{array}$ \\
\hline $78 / 26$ SRAW & 64.08 & 94.73 \\
\hline
\end{tabular}

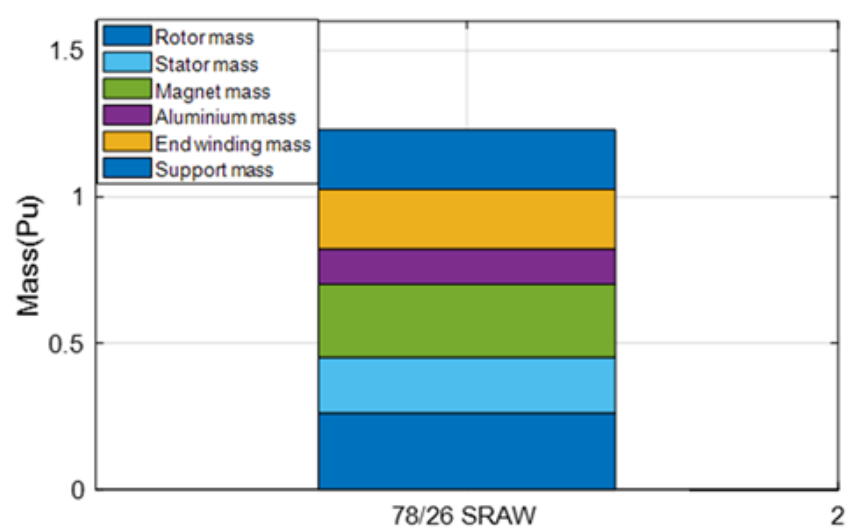

Fig 10: Masses of different parts of SRAW machine

\section{COMPARISON OF ALL THE TOPOLOGIES}

The best models of each topology were compared based on the efficiency at cruise condition and overall mass. Table 4 shows the efficiencies of the best model obtained from the optimiser at take-off and cruise condition. Fig 11 shows the masses of different parts of each machine normalising it with the mass of individual parts of the 27/36 laminated design. It is important to mention that all the machines fulfil the takeoff condition which indirectly determines the size of the machine due to the high torque demand at that point. 
Table 4: Efficiencies of all machines at take-off and cruise condition

\begin{tabular}{|c|c|c|}
\hline & $\begin{array}{c}\text { Take-off condition } \\
(\%)\end{array}$ & $\begin{array}{c}\text { Cruise } \\
\text { condition }(\%)\end{array}$ \\
\hline 27/36 laminated & 78.14 & 96.24 \\
\hline $78 / 26$ DRHW & 77.30 & 97.00 \\
\hline $78 / 26$ SRAW & 64.08 & 94.54 \\
\hline
\end{tabular}

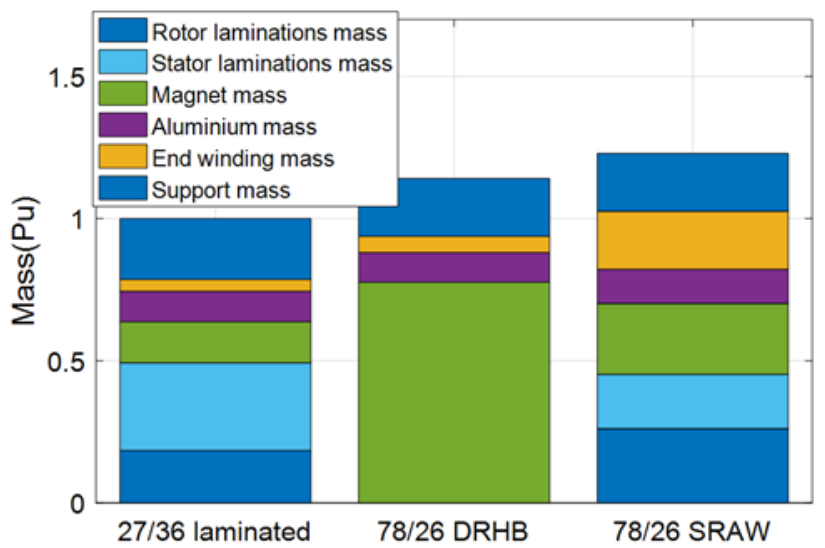

Fig 11: Mass comparison of different machines

It is clear from the above table and figure that the $27 / 36$ laminated steel design is the best based on its lower mass (18\% less mass compare to 78/26 DRHB model) while achieving an efficiency which is only $0.8 \%$ lower compare to the 78/26 DRHW design meaning that it ends up with a superior objective function. Therefore, the 27/36 laminated steel design was chosen as the best candidate for further loss analyses.

\section{LOSSES ANALYSES}

\section{A. AC losses}

During the cruise condition, the temperature of both the magnets and aluminium wire is very low $\left(-40^{\circ} \mathrm{C}\right.$ expected $)$. This increases the remanence of the magnets which can extend the magnet flux deeper within the stator slot. This can result in high eddy current losses within the coils due to high electrical conductivity of the wire at low temperatures. Due to the compressed aluminium windings, drawing each conductor individually within the 2DFE model is complicated. To overcome this, the square field derivate (SFD) method was used [17]. The method is based on finding the flux density across the slot at each time step. The loss per slot can then be found by using equation (1)

$$
P_{a c}=\frac{\pi}{64} \cdot \sigma \cdot l \cdot d^{4} \cdot \frac{d B^{2}}{d t}
$$

Where $\sigma$ is the conductivity of the material (aluminium in this case), 1 and $\mathrm{d}$ are the length and diameter of the conductor, and $\mathrm{B}$ is the flux density at a certain point in a certain time.

From the FEA software, the flux density (B) values within the slot at different point and different time steps was found per electrical cycle. In this case the number of steps per electrical cycles was 60 . The Matlab script distributes the number of turns/slot and number of strands/turn equally across the slot.

By knowing the number of slots, stack length, number of turns per slot, diameter of each conductor and conductor resistivity at a certain temperature $\left(-40 C^{\circ}\right.$ in this case), the $\mathrm{AC}$ loss was found by using equation (1). Fig 12 shows the reduction in $\mathrm{AC}$ losses as the number of strands within fixed wire diameter varies for the same fill factor.

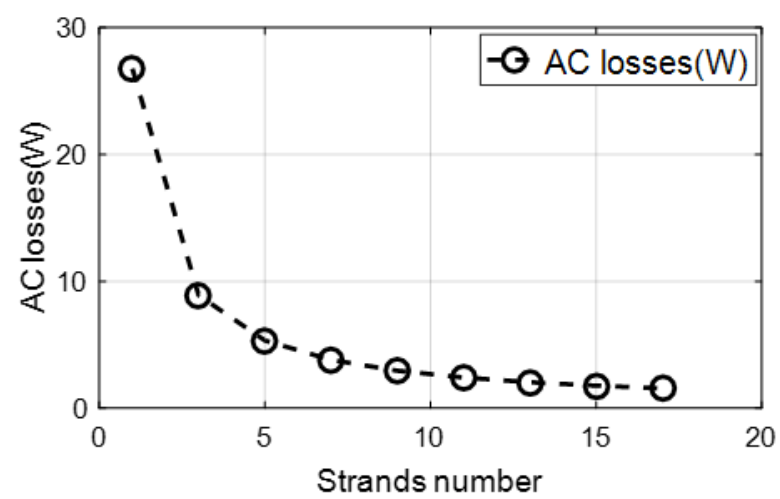

Fig 12: AC losses for different strands number

The above figure shows that above a certain strands number, there is a very low decrease in AC losses. Therefore using an excessively high strands wire is not a good option as it will decrease the fill factor due to sizable insulation thickness.

\section{B. Magnet losses}

3D FEA analysis of the final design was done to assess the magnet losses. The machine was simulated at the peak speed. In PM synchronous machines, the stator space harmonics and PWM harmonics induce surface currents on the permanent magnets [18-20]. This can increase the temperature of the magnets which in turn decreases their remanence. To reduce these losses, the magnet was segmented axially. Fig 13 shows the reduction of magnet losses due to segmentation. The segmentation results in $95 \%$ reduction in magnets losses when the magnet segment length was reduced.

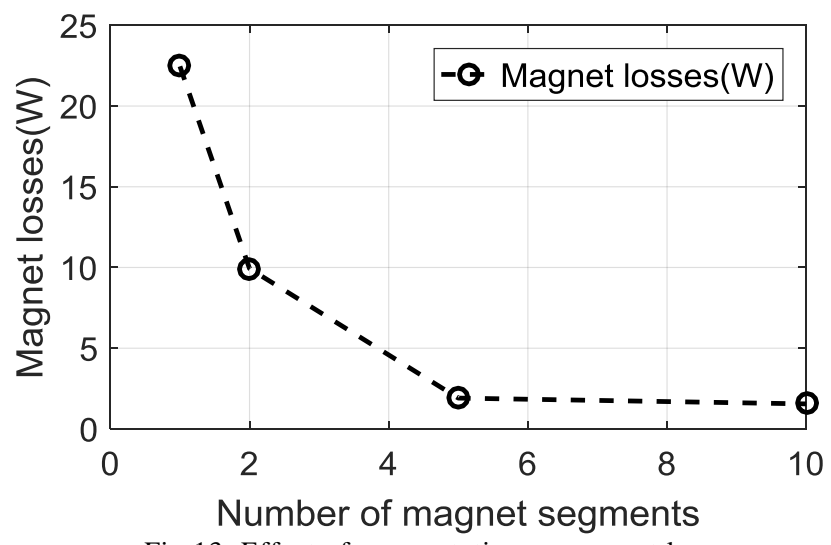

Fig 13: Effect of segmentation on magnet losses

By including the AC and magnet losses within the final results, the overall efficiency of the machine found was $95.2 \%$. 


\section{CONCLUSION}

Different PM machine topologies were investigated to find the best design with respect to minimising objective function that values lower mass, high efficiency and small diameter in a machine. All machines were optimised for cruise condition while fulfilling a thermal constraint at the take-off condition. Based on the results, the DRHB topology showed a maximum efficiency of $97 \%$ predominantly due to lack of iron losses. However, the mass of the machine was $18 \%$ more compared to the laminated 27/36 topology which achieved an efficiency of $96.4 \%$ (excluding magnet and AC losses). Therefore, the 27/36 topology was chosen as the best topology based on maximizing the objective function.

The chosen topology was further simulated to find the magnet and AC losses. The AC losses decreased significantly by increasing the strands number, however, there was a limit to the strands number as it affects the fill factor which in turn increases the DC copper loss. Axial segmentation of the magnets resulted in a $95 \%$ reduction in losses as the axial length of the magnet reduces from $10 \mathrm{~mm}$ to $1 \mathrm{~mm}$. The efficiency of the best topology found was $95.2 \%$.

\section{REFERENCES}

[1] R. J. Boucher, "History of Solar Flight," in 20th Joint Propulsion Conference, Cincinnati,Ohio, USA, 1984.

[2] "NASA Dryden Factsheets:Helios Prototype[online] Available at"https://www.nasa.gov/centers/dryden/pdf/120318main_FS068-DFRC.pdf"."

[3] B. C. Mecrow, J. W. Bennett, A. G. Jack, D. J. Atkinson, and A J. Freeman, "Drive Topologies for Solar-Powered Aircraft," IEEE Transactions on Industrial Electronics, vol. 57, no. 1, pp. 457-464, 2010.

[4] "Solar impulse"https://solarimpulse.com/" "

[5] "Facebook electrical machine for widespread internet"https://www.facebook.com/notes/mark-zuckerberg/thetechnology-behind-aquila/10153916136506634/"."

[6] "JFE Steel Corporation data sheet for JFE Super Core JNEX900"http://www.jfe-

steel.co.jp/en/products/electrical/catalog/f2e-001.pdf".

[7] J. D. Widmer, R. Martin, and B. C. Mecrow, "Pre-compressed and stranded aluminium motor windings for traction motors." pp. 1851-1857.

[8] J. D. Widmer, C. M. Spargo, G. J. Atkinson, and B. C. Mecrow, "Solar Plane Propulsion Motors With Precompressed Aluminum Stator Windings," IEEE Transactions on Energy Conversion, vol. 29, no. 3, pp. 681-688, 2014.

[9] M. Popescu, D. G. Dorrell, D. Ionel, and C. Cossar, "Single and double layer windings in fractional slot-per-pole PM machines effects on motor performance." pp. 2055-2060.

[10] K. Wang, Z. Q. Zhu, and G. Ombach, "Synthesis of High Performance Fractional-Slot Permanent-Magnet Machines With Coil-Pitch of Two Slot-Pitches," IEEE Transactions on Energy Conversion, vol. 29, no. 3, pp. 758-770, 2014.

[11] A. G. Jack, B. C. Mecrow, and J. A. Haylock, "A comparative study of permanent magnet and switched reluctance motors for high-performance fault-tolerant applications," IEEE Transactions on Industry Applications, vol. 32, no. 4, pp. 889895, 1996.

[12] B. C. Mecrow, A. G. Jack, D. J. Atkinson, S. R. Green, G. J. Atkinson, A. King, and B. Green, "Design and testing of a fourphase fault-tolerant permanent-magnet machine for an engine fuel pump," IEEE Transactions on Energy Conversion, vol. 19, no. 4, pp. 671-678, 2004.

[13] J. Ofori-Tenkorrang, and J. H. Lang, "A comparative analysis of torque production in Halbach and conventional surface-mounted permanent-magnet synchronous motors." pp. 657-663 vol.1.

[14] H. C. Lovatt, V. S. Ramsden, and B. C. Mecrow, "Design of an in-wheel motor for a solar-powered electric vehicle." pp. 234 238.
[15] N. Borchardt, R. Hinzelmann, D. S. Pucula, W. Heinemann, and R. Kasper, "Winding Machine for Automated Production of an Innovative Air-Gap Winding for Lightweight Electric Machines," IEEE/ASME Transactions on Mechatronics, vol. 21, no. 3, pp. 1509-1517, 2016

[16] "Tango Brushless Motors manufactured by Kontronik," http://www.kontronik.com/en/products/motors/tango/tango45.html.

[17] C. R. Sullivan, "Computationally efficient winding loss calculation with multiple windings, arbitrary waveforms, and two-dimensional or three-dimensional field geometry," IEEE Transactions on Power Electronics, vol. 16, no. 1, pp. 142-150, 2001.

[18] P. Sergeant, and A. V. d. Bossche, "Segmentation of Magnets to Reduce Losses in Permanent-Magnet Synchronous Machines," IEEE Transactions on Magnetics, vol. 44, no. 11, pp. 44094412, 2008.

[19] M. Nakano, H. Kometani, and M. Kawamura, "A study on eddycurrent losses in rotors of surface permanent-magnet synchronous machines," IEEE Transactions on Industry Applications, vol. 42, no. 2, pp. 429-435, 2006

[20] F. Chai, P. Liang, Y. Pei, and S. Cheng, "Magnet Shape Optimization of Surface-Mounted Permanent-Magnet Motors to Reduce Harmonic Iron Losses," IEEE Transactions on Magnetics, vol. 52, no. 7, pp. 1-4, 2016.

\section{BIOGRAPHIES}

Sana Ullah received BSc degree in 2008 from UET Peshawar, Pakistan. He got his MSc degree in Electrical Power in 2011 and $\mathrm{PhD}$ degree in 2016 from the University of Newcastle. He is currently working as a research assistant in the University of Newcastle, Engineering department. His research interests include the design and analysis of permanent magnets and switched reluctance machines.

Mohammad Kimiabeigi received the BEng, MSc and $\mathrm{PhD}$ degrees in electric power engineering from Isfahan University of Technology, Iran 2006, Royal Institute of Technology, Sweden 2008, and Newcastle University, UK 2017. Since 2007 he has been a research engineer at ABB competence center, Sweden, Siemens Wind Power, Denmark, and Siemens Wind Power competence center, UK, and currently a senior research associate at Newcastle University, UK

Dr Kimiabeigi holds 12 granted European and U.S patents, 22 filed patent applications, and over 30 journal and peer reviewed conference publications. During his career, he has been a lead design engineer for $\mathrm{R} \& \mathrm{D}$ projects over a variety of renewable, automotive, and energy sectors, and is currently a principal and co-investigator in number of research grants, with a total value of over $£ 3 \mathrm{M}$, where he develops electromagnetic solutions for land, marine, and aerospace applications.

Ben Scholes was born in Wiltshire, UK in 1992. He received a first class MEng (Hons) degree in Mechanical and Low Carbon Transport Engineering from Newcastle University, Newcastle Upon Tyne, UK in 2016.

During his degree he took a voluntary industrial placement for a year with Triumph Motorcycles and since graduating has worked as a research assistant at the Centre for Advanced Electrical Drives, part of the Electrica Power Research Group in the School of Engineering at Newcastle University, UK. His research interests cover mechanical design aspects of traction motors, in particular switched reluctance type machines.

Andy Steven has a degree in Mechanical Engineering, a PhD in robotics and is a specialist in electro-mechanical engineering. He has worked in industry in this market sector.

$\mathrm{He}$ also has worked in transmission research and has designed a number of transmission research machines to carry out transmission studies. He also innovated a method of measuring internal bearing loads in large rolling contact bearings and a method light-weighting gears.

He has also designed the mechanical structure of a number of high speed electrical research machines along with their integrated speed reduction transmissions. He now works as a Senior Research Associate within the Centre for Advanced Electrical Drives, School of Engineering, Newcastle University.

He has a number of patents and papers in various areas of engineering. 
William Davis received an M.Eng. degree in Aeronautical Engineering from the University of Bristol, U.K., in 1999. He currently works as a Systems Engineer for Airbus UK and has been responsible for delivering electric propulsion systems for high altitude UAVs since 2009.

Rafal Wrobel received the M.Sc.Eng. degree from the Opole University of Technology, Opole, Poland, in 1998; the Ph.D. degree from the Lodz University of Technology, Lodz, Poland, in 2000; and the habilitation degree from Opole University of Technology, Opole, Poland, in 2013. He is a Senior Research Associate at the Centre for Advanced Electrical Drives, Newcastle University, Newcastle upon Tyne, UK. Rafal's research interests include multidisciplinary 'design for application' of electrical machines, transformers and wound passive components.

James Widmer received the M.Eng. degree in electrical and electronic engineering from the University of Bristol, U.K., in 1998. He is currently working toward the Ph.D. degree in electrical machine design in the School of Electrical and Electronic Engineering, Newcastle University, Newcastle upon Tyne, U.K. He joined Newcastle University in 2009 from a senior post in the aerospace industry. He is responsible for the "Centre for Advanced Electrical Drives," Newcastle University which works with industry partners to convert academic research into world-class products. His research interests include high-efficiency permanent magnet machines and rare-earth magnet-free motor topologies. 